\title{
Correction: Text Messaging Versus Email Messaging to Support Patients With Major Depressive Disorder: Protocol for a Randomized Hybrid Type II Effectiveness-Implementation Trial
}

Medard Kofi Adu ${ }^{1 *}$, BSc, MSc; Reham Shalaby ${ }^{1 *}$, MD; Ejemai Eboreime ${ }^{1}, \mathrm{MD}, \mathrm{PhD}$; Adegboyega Sapara ${ }^{1}, \mathrm{PhD}$, FRCPC; Nnamdi Nkire ${ }^{1}$, MD, MBBS, DHSM, DCP, FRAMI; Rajan Chawla ${ }^{1}$, MBBS, CCT, MSC, MRCPsych; Chidi Chima $^{1}$, MBBS, MPH, PhD; Michael Achor ${ }^{1}$, MD, MSc, FRCPC; Felix Osiogo ${ }^{1}$, FRCPC, FWACS, CCT-UK, MBBS; Pierre Chue ${ }^{1}$, MD, DABPN, MRCPsych, FRCPC; Andrew J Greenshaw ${ }^{1}$, PhD, FRSA; Vincent Israel Agyapong ${ }^{1,2}$, $\mathrm{MD}, \mathrm{PhD}$, FRCPC, FRCPsych

\footnotetext{
${ }^{1}$ Department of Psychiatry, Faculty of Medicine and Dentistry, University of Alberta, Edmonton, AB, Canada

${ }^{2}$ Department of Psychiatry, Faculty of Medicine, Dalhousie University, Halifax, NS, Canada

*these authors contributed equally
}

\section{Corresponding Author:}

Vincent Israel Agyapong, MD, PhD, FRCPC, FRCPsych

Department of Psychiatry

Faculty of Medicine

Dalhousie University

5909 Veterans' Memorial Lane

8th Floor Abbie J. Lane Memorial Building QEII Health Sciences Centre

Halifax, NS, T6G 2B7

Canada

Phone: 17807144315

Email: agyapong@ualberta.ca

\section{Related Article:}

Correction of: https://www.researchprotocols.org/2021/10/e29495

(JMIR Res Protoc 2021;10(11):e34515) doi: 10.2196/34515

In "Text Messaging Versus Email Messaging to Support Patients With Major Depressive Disorder: Protocol for a Randomized Hybrid Type II Effectiveness-Implementation Trial" (JMIR Res Protoc 2021;10(10):e29495) the authors noted two errors.

1. In the originally published paper, author affiliations 1 and 2 were numbered incorrectly. The numbering of these affiliations has been switched in the corrected paper.

2. The equal contribution symbol ' $*$ ' for author Felix Osiogo has been removed.

The complete list of authorship and affiliations was originally published as follows:

Medard Kofi $A d u^{1 *}, B S c, M S c$; Reham Shalaby ${ }^{1^{*}}$, MD; Ejemai Eboreime ${ }^{l}, M D, P h D ;$ Adegboyega Sapara $^{l}$, PhD, FRCPC; Nnamdi Nkire ${ }^{l}, M D, M B B S$, DHSM, DCP, FRAMI; Rajan Chawla ${ }^{l}, M B B S, C C T$, MSC, MRCPsych; Chidi Chima ${ }^{l}, M B B S, M P H, P h D$; Michael Achor ${ }^{l}$, MD, MSC, FRCPC; Felix Osiogo ${ }^{1 *}$, FRCPC, FWACS, CCT-UK, MBBS; Pierre Chue ${ }^{l}$, $M D, D A B P N$, MRCPsych, FRCPC; Andrew $J$
Greenshaw $^{l}$, PhD, FRSA; Vincent Israel Agyapong ${ }^{1,2}$, $M D, P h D, F R C P C$, FRCPsych

${ }^{1}$ Department of Psychiatry, Faculty of Medicine, Dalhousie University, Halifax, NS, Canada

${ }^{2}$ Department of Psychiatry, Faculty of Medicine and Dentistry, University of Alberta, Edmonton, $A B$, Canada

* these authors contributed equally

This has been corrected to the following:

Medard Kofi Adu ${ }^{1^{*}}$, BSc, MSc; Reham Shalaby ${ }^{{ }^{*}}$, $M D$; Ejemai Eboreimel, MD, PhD; Adegboyega Saparal, PhD, FRCPC; Nnamdi Nkire ${ }^{l}, M D, M B B S$, DHSM, DCP, FRAMI; Rajan Chawla ${ }^{l}, M B B S, C C T$, MSC, MRCPsych; Chidi Chima ${ }^{1}, M B B S, M P H, P h D$; Michael Achor ${ }^{l}$, MD, MSC, FRCPC; Felix Osiogo ${ }^{l}$, FRCPC, FWACS, CCT-UK, MBBS; Pierre Chue ${ }^{l}$, $M D, D A B P N$, MRCPsych, FRCPC; Andrew $J$ Greenshaw $^{l}$, PhD, FRSA; Vincent Israel Agyapong ${ }^{1,2}$, $M D, P h D, F R C P C$, FRCPsych 
${ }^{1}$ Department of Psychiatry, Faculty of Medicine and Dentistry, University of Alberta, Edmonton, $A B$, Canada

${ }^{2}$ Department of Psychiatry, Faculty of Medicine, Dalhousie University, Halifax, NS, Canada

*these authors contributed equally
The correction will appear in the online version of the paper on the JMIR Publications website on November 5, 2021, together with the publication of this correction notice. Because this was made after submission to PubMed, PubMed Central, and other full-text repositories, the corrected article has also been resubmitted to those repositories.

This is a non-peer-reviewed article. Submitted 27.10.21; accepted 27.10.21; published 08.11.21.

Please cite as:

Adu MK, Shalaby R, Eboreime E, Sapara A, Nkire N, Chawla R, Chima C, Achor M, Osiogo F, Chue P, Greenshaw AJ, Agyapong $V I$

Correction: Text Messaging Versus Email Messaging to Support Patients With Major Depressive Disorder: Protocol for a Randomized Hybrid Type II Effectiveness-Implementation Trial

JMIR Res Protoc 2021;10(11):e34515

URL: https://www.researchprotocols.org/2021/11/e34515

doi: $10.2196 / 34515$

PMID:

CMedard Kofi Adu, Reham Shalaby, Ejemai Eboreime, Adegboyega Sapara, Nnamdi Nkire, Rajan Chawla, Chidi Chima, Michael Achor, Felix Osiogo, Pierre Chue, Andrew J Greenshaw, Vincent Israel Agyapong. Originally published in JMIR Research Protocols (https://www.researchprotocols.org), 08.11.2021. This is an open-access article distributed under the terms of the Creative Commons Attribution License (https://creativecommons.org/licenses/by/4.0/), which permits unrestricted use, distribution, and reproduction in any medium, provided the original work, first published in JMIR Research Protocols, is properly cited. The complete bibliographic information, a link to the original publication on https://www.researchprotocols.org, as well as this copyright and license information must be included. 